\title{
A SMALL STEP TOWARD INTEROPERABILITY
}

\author{
Ronald J. ROLAND
}

\section{Content Focus}

Never forget, the lowest bidder made your weapons

Applying simulations to enhance jointness and to promote national and multi-national cooperation and interoperability. The theory is that this will help lead toward developing a Modeling and Simulation (M\&S) Master Plan for emerging Democratic Countries and enhance military and crisis management interoperability. Advances that have occurred since the 1999 with issues of Information and Security and dealing with the increased capabilities and continued proliferation of the Joint Theater Level Simulation (JTLS), emphasizing the interoperability issues, and the inherent dangers in the proliferation and quick fix approach of a variety of simulations in the wake of the terrorist event of 9/11/01. There are no quick fixes. Simulation users are learning the hard way by being seduced into the "pit" of simulation tools.

A subordinate focus includes the extent to which one theater level simulation has increased its capabilities, functionalities and user base; and its' relationship with the National Military Command Center (NMCC) initiative. Caution is extended for the user to exercise due diligence and caveat emptor when selecting systems and system integrators.

\section{Coverage}

Tracers work both way

This paper will address the critical issues that have been resolved toward meeting the NMCC requirements of providing a common simulation software environment for both crisis management coordination at the intra and international levels and a potential candidate that can be used for combined, joint and coalition training of combat and security forces. It will propose a common architecture for the NMCC concept and support the guidelines of North Atlantic Treaty Organization (NATO) 
M\&S. Information and guidelines will be provided concerning future enhancements programmed for JTLS and how each user can help guide continued upgrades and revisions. The proliferation of $M \& S$ related tools, use of the term $M \& S$ (and its image, S\&M), technology developers and claims of value are discussed. Caveat emptor is defined to mean that simulation users should be technologically competent and use expert judgment in their selection and acceptance of simulation technology.

\section{Preface}

If you think education is expensive, try ignorance ${ }^{l}$

It seemed clear at the outset of this contribution that the focus should be on the dichotomy of what most simulation users think is meant by the term Modeling and Simulation, shortened to M\&S, and the ensuing liberties taken by some software developers to pursue and market the analogous works of Smoke and Mirrors, fondly shortened to S\&M. ${ }^{2}$ Hence the original title selected was Smoke and Mirrors ( $S \& M$ ) as the Antithesis of Modeling and Simulation $(M \& S)$. As this research developed, it became apparent that the lack of interoperability at multiple levels, military as well as civil coordination, was a very key issue; and that a great deal of data indicate at least one M\&S application was making a difference. The following is an effort to highlight some of the issues, respective players and define an opportunity to overcome the interoperability training shortfalls.

\section{Introduction}

When the enemy is in range, so are you

The international journal, Information \& Security, volume 3, published in 1999, included an article on $M \& S$ techniques and their applications to security related issues including defense, internal security and international cooperation. Since then, the value of simulations to defense establishments has been repeatedly proven by providing readily available, operationally valid environments to (1) train jointly, develop doctrine and tactics, formulate operational plans, (2) assess warfighting situations, and (3) support technology assessment, system upgrade, prototype and full-scale development, and force structuring. The corollary to M\&S is Smoke and Mirrors or S\&M. S\&M has proven a deadly counterpart to achieving cost efficient simulation capabilities. ${ }^{3}$ Two key events occurred during preparation of this material. One was a memorandum by the U.S. Office of the Secretary of Defense that directed that development efforts on the Joint Simulation System (JSIMS) be funded only through Fiscal Year 2003 and follow on efforts be reviewed or discontinued ${ }^{4}$ pending review by the Office of Secretary of Defense, the Joint Staff and the services. JSIMS had become almost a billion dollar, multi-year investment that continued to 
experience technical and management problems. Its termination was probably a very difficult political decision. The Joint Forces Command and the JSIMS program office have been instructed to capture the lessons learned (good and bad) for future simulation developers. The spiral approach for example was a key element of the JSIMS development. This relatively new methodology may not have been a sound methodology for such an undertaking. Was this M\&S or S\&M? We will not know unless and until the report is written and evaluated to be either a real lessons learned or an attempt to justify the expenditure of a huge sum of money on a catastrophe. We hope $S \& M$ is not the result.

The second event was a meeting of members from PEO-STRI, USJFCOM, NAWCTSD, USAF/ESC and MSIAC called the Enterprise Team, who reaffirmed their organizations' resolution to promote interoperability programs in the European and Balkan regions. ${ }^{5}$ The USAF/ESC representative presented changes to the NMCC concept, which were included to promote interoperability from the tactical through the operational to the strategic leadership levels of cooperating nations.

The article titled Applying Modeling and Simulation To Enhance National and MultiNational Cooperation by the author of this paper provided a background concerning one effort, the USAF/ESC NMCC initiative. The focus was to proliferate a common architecture for crisis management, a history of simulation development and an introduction to a specific software application, the Joint Theater Level Simulation (JTLS). JTLS is used throughout the world to train senior staffs within simulated crises situations. ${ }^{6}$ It focused on the potential use of simulations, and their scientific bases, for application to crisis management. The emphasis was on using simulation software that was widely available, currently in use by several U.S. and non-U.S. agencies, was an open system architecture, was well documented, configuration managed, could be (and generally is) used with LANs as well as WANs, and was database driven. ${ }^{7}$ The recommended simulation, JTLS, met all these criteria in 1999 and currently exceeds them. It is used for Computer Assisted Exercises (CAXs) involving joint, combined and multinational training to include analysis of the training events and the capability to be used as an analysis tool independent of training. This paper describes the continued application of simulation technologies to enhance country-to-country, agency-to-agency and coalition-to-coalition cooperation and understanding. It describes a potential synergism between the proposed capabilities of the NMCC and the inherent features contained in the current release of the JTLS software.

The Chief of Initiatives, Joint Training Directorate, U.S. Joint Forces Command, U.S. Joint Warfighting Center, recently stated that training for joint military operations is the key for success on the battlefield and must be an element in future military simulations. Colonel Ann Campbell was describing the establishment of a U.S. Joint 
National Training Center. She further stated "this training center will provide a seamless training environment across a broad spectrum of training requirements. ", She emphasized joint training as a key to transformation to facilitate tightly coupled interactions among the training, operations and acquisition communities to meet their respective tasks. The need to enhance interoperability among the NATO Alliance Members, Partnership for Peace (PfP) Nations and the Mediterranean Dialogue Countries was articulated by Lord Robertson in his presentation, The Transatlantic Security Agenda. ${ }^{9}$ He pointed out that part of the agenda include crisis management, regional issues, international terrorism, civil emergencies and disaster preparedness.

Mr. Young, U.S. Naval Postgraduate School, reviewed many of the issues facing C2 interoperability in the European theater. ${ }^{10}$ Standard practices, policies and procedures headed the list. The increased use of command post exercises and computer-assisted simulations were at the top of his list of recommendations. An excellent example of this lack of operational capability was the challenges of Task Force Hawk, described by Gordon and colleagues. ${ }^{11}$ They identified major failures in the integration of NATO ground and air forces. Achieving interoperability is a key element, where European member states are trying to further develop their capabilities as part of NATO's Defense Capabilities Initiative and trying to achieve the goals of the European Union's (EU's) European Security and Defense Policy. The spokeswoman for the NATO Military Exercise Branch, Ms. Karen Dehaes, stated, "due to the multinational and joint character of allied operations, coherence and interoperability between national force contributions have to be enhanced." 12

These same environments can support the implementation of a national command center for crisis management. One environment, discussed in 1999 is the Joint Theater Level Simulation system. ${ }^{13}$ The architectural enhancements to the simulation software, the continued implementation of faster, cheaper and more available hardware and operating systems, the forthcoming delivery of a Web-enabled version, and its recent use in multi-national environments dealing with scenarios specifically focused on Operations Other Than War (OOTW), combine to provide a simulation environment that coincides with the NMCC concepts.

This command center, identified as the NMCC, would support both national civil and military crisis situations. It would also support regional collaboration in response to regional crisis situations because different national systems would be built on a common architectural platform, This NMCC concept is to be constructed from affordable, reusable components interoperating through open systems architecture to allow maximum utility and flexibility.

Dr. Warren Switzer provided an excellent example on OOTW and the use of simulations to mitigate the time lag between identifying a potential problem and 
being able to use the tools for either training or evaluation. ${ }^{14} \mathrm{He}$ described the need to be able to simulate interoperability among the various civil authorities as well as military organizations. The emphasis was the importance of information exchange at multiple levels throughout the decision-making hierarchy and the development of standard procedures to make it happen.

\section{The National Crisis Management Command Center}

Incoming rounds have the right of way

The demise of the Warsaw Pact in 1989, the continued growth of the European Union, NATO, and the Partnership for Peace (PfP) consortium, have changed the political landscape of the world. These changes, coupled with the continuing changes in military and political environments, threats, acts of terrorism, and natural disasters, continue to generate crisis situations within and beyond national boundaries. None of these events recognize political boundaries. Collaboration and interoperability with multi-national resources is essential. ${ }^{15}$

The recent NATO summit in Prague opened a new opportunity to transform NATO's role in trans-Atlantic defense industrial and technological cooperation according to Professor Gordon Adams. ${ }^{16}$ NATO partners made substantial progress on a long-term agenda to change the role and structure of the alliance. A rapid-reaction force was identified as a critical element to support the alliance.

Eight key capability objectives, critical to future alliance interoperability, were identified. Five of the eight are associated with implementation of simulation capabilities within the previously discussed NMCC conceptual architecture. These are: (1) the rapid reaction force will depend on interoperable $\mathrm{C}^{4} \mathrm{ISR}$; (2) the alliance needs to develop coalitions that encourage the sharing of data and technology, engage in cooperative $\mathrm{R} \& \mathrm{D}$, and increase joint procurement of weapons and communications; (3) the new transformation command in Norfolk, VA (Formerly SACLANT), must integrate transformational technologies into European forces; (4) a joint transAtlantic system will depend on linkages among radar and information technologies for more flexible information transfer; and (5) European allies must increase and integrate their spending on research and development, especially on technologies related to the Prague initiatives.

An important result of the meetings in Prague was that the alliance's command structure was altered, transforming the Atlantic Command into an allied transformation command, focusing on alliance-wide adoption of $21^{\text {st }}$ century defense technologies. 
There are at least three key fundamental requirements for civil and military components to be able to respond to crisis situations in an efficient manner: (1) the availability of information regarding crisis situations and military/civil resources readiness; (2) coordination among the organizations and agencies (intra and international) involved in crisis management; and (3) continued training and exercising of the resources so that they can respond effectively when needed. The U.S. Air Force has provided architecture to support the operational aspects of an information system intended to assist national Ministries of Defense (MODs) in arriving at a solution for these issues. ${ }^{17}$ This proposed solution was discussed in the previous article and remains in the planning stage. The NMCC concept was presented to several nations in the spring of 1999 and met with favorable response. The presentation identified the Joint Theater Level Simulation (JTLS) as a potential baseline for training and analysis at the national and multi-national command and decision-making levels. ${ }^{18}$

The U. S. government formally introduced the new policy initiative to Partnership for Peace nations at a multinational conference in Sofia, Bulgaria, in June 1999. The U. S. keynote address at the conference, described the NMCC as an initiative to provide national command authorities with a modern, integrated command and control center to support decision-making in the event of civil or military crises. Further, the NMCC would be built on a NATO-compatible technical architecture platform and provide interfaces compatible with comparable NATO and U.S. command and control systems. Currently only two countries have agreed to become associated with this concept.

\section{Simulation Support}

The enemy diversion you have been ignoring will be the main attack

The previous article provided an extensive summary of modeling and simulation $(\mathrm{M} \& S)$ agencies and activities including the High Level Architecture, Joint and Service efforts, various associations and current research. A variety of simulations were discussed. It included an in-depth discussion of the Joint Theater Level Simulation (JTLS) as an illustration of a joint war-gaming system. ${ }^{19}$ The purpose was to illustrate a software capability that might enhance the NMCC concept and exploit a great deal of simulation software developed by NATO Consultation and Control Agency (NC3A). Figure 1 shows different scenarios in which the NMCC and JTLS combination could support. 


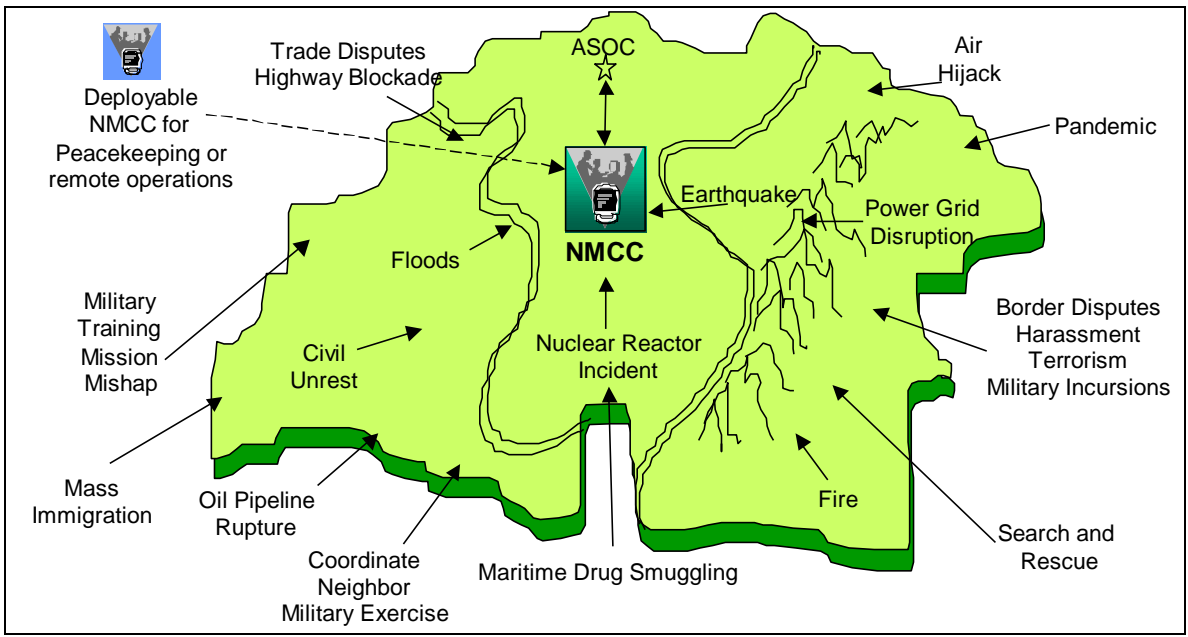

Figure 1: NMCC and JTLS Support to Crisis Management Operations.

\section{JTLS since 1999}

If your attack is going well you have walked into an ambush There have been approximately eight minor releases and three major releases per year of the JTLS software since the first meeting in 1999. Each release is fully controlled by the JFCOM/JWFC Program Management Office and through a formal Configuration Control Board (CCB) and is accompanied by a complete suite of current documentation. ${ }^{20}$ The simulation is used in approximately six major U.S. Joint exercises per year and about the same for International users of JTLS. ${ }^{21}$ These International (non-U.S.) users include eleven current JTLS installations and six pending for $2003 .{ }^{22}$ The JWFC/JFCOM commitment to the JTLS user community is administered through a support contractor and is designed to provide sufficient training so they can use JTLS effectively without continued external support. This does not mean to imply that the users are without recourse if they have problems or technical questions. A 24/7 help desk is available for all JTLS users. This particular support strategy has been very successful from the JWFC/JFCOM perspective.

Enhancements to the JTLS simulation engine are too numerous to mention in this article. A major revision is planned annually with intervening deliveries as needed. The help desk support and deliveries are accomplished via the web, email, fax or CD deliverers. Three recent training exercises, US Pacific Command's (PACOM's) Terminal Fury, NATO's CANNON CLOUD and US Central Command's (CENTCOM's) Internal Look, are examples of the capability of JTLS to support 
multiple users of various nationalities around the world simultaneously. ${ }^{23,24,25}$ The exercises were two, two and one half and two weeks long respectively. All were 24/7. The simulation model downtime that the users experienced throughout any exercise was less than 40 minutes total.

The current enhancements to JTLS include porting the source code to the Linux operating system (OS). While the JTLS Player Stations have always included PCs as well as Sun workstations, the requirement for the SUN Solaris OS remained constant. JTLS Version 2.5, delivered to the JFCOM/JWFC JTLS Program Manager in January 2003 by their support contractor, includes object code for both SUN Solaris and Linux OS. ${ }^{26}$ This version of JTLS has been tested and used in USPACOM's Terminal Fury CAX. Both laptops and desktop PCs were used for the very successful two-week effort. Integration with other systems, for example C4ISR capabilities, continues at each exercise. The NC3A exercise called CANNON CLOUD is an excellent example of a theater missile defense scenario where the theater level, missile and $\mathrm{C} 2$ simulations were exchanging data. ${ }^{27}$

Another enhancement to the JTLS repertoire is the current design/integration of the JTLS and Joint Conflict and Tactical Simulation (JCATS) simulations. JCATS is the only self-contained inherently joint simulation in use for entity-level training in open, urban, and subterranean environments. JCATS is an interactive, high resolution, entity level, conflict simulation that models joint-multi-sided air, ground, and sea combat on high-resolution, digitized, polygonal terrain. The uses of JCATS range from the joint task force level to tactical and operations other than war levels in scenarios including open, urban, and subterranean environments using aggregated and individual systems. JCATS' most unique features include the replicating of small group tactics in urban terrain to include enhanced multi-floor buildings with doors, windows, interior walls, day-night operations under differing visibility and artificial lighting to include an underground environment.

JCATS is being developed and maintained by the Lawrence Livermore National Laboratory (LLNL). However, its Program is managed and funded by the Director for Joint Force Training at JFCOM/Joint Warfighting Center. The integration of JTLS and JCATS will represent a breakthrough in simulations for many reasons. Both models are established world wide meeting user requirements. This combination will provide, for the first time, a single simulation suite that can be used at the theater and operational levels simultaneously. They are both High Level Architecture (HLA) compliant, both run on PCs, and are managed by a single U.S. agency, the JFCOM/JWFC, and they are both available to international users. JTLS may be obtained through FMS or commercially. JCATS can only be obtained via FMS. Delivery of this JTLS/JCATS HLA integrated system is scheduled in late 2003. There are ongoing studies to include other simulations as part of the JTLS/JCATS 
architecture, which will provide a more robust presentation in the training environment. These initiatives include logistics, intelligence, air defense enhancements and civil agencies.

Simulations have historically been developed with unique graphic user interfaces, also known as human computer interfaces. The concept of being able to use a common browser for such applications has evolved with the increasing speed of the Internet. JTLS has a prototype Web enabled capability in beta test. It has been used in parallel in one major U.S. International CAX with great success. This version of JTLS, most likely assigned Version 3.0, will include a Web capability in addition to the Linux and SOLARIS operating system instantiations. The ability of a PC to become a JTLS Workstation, (regardless of the PC OS platform being used) will greatly reduce the cost of standing up a simulation center by populating it with laptops and desktop PCs. Taking the simulation to the hands of the users in such a cost effective manner should greatly increase the number of experienced participants, thereby increasing the interoperability of the community of users.

\section{Current Value}

Never draw fire, it irritates everyone around you

The current value of employing simulation tools, such as JTLS, is obvious to those of us who are constantly in the field. This benefit to the interoperability issue is not so evident to others, so some amplification is appropriate. Using simulations is becoming a standard part of the training and exercise schedules of most modern armed forces and many civil agencies. In addition, simulations have been used for years to conduct analyses and experiments that where either far too dangerous to actually conduct or too expensive. Simulations also allow civil and military staffs to do almost real-time mission planning and rehearsal. The tradeoff is that a staff must be trained and available to support the myriad detail that is involved with maintaining the software, the hardware and the data.

The use of JTLS provides insight into many of the interoperability issues. For example, the Southeastern Europe Simulation (SEESIM) exercise that was conducted in December 2002 demonstrated the value of using such a simulation tool. SEESIM was mandated by the Southeastern European Defense Ministers (SEDM) to integrate initiatives through a series of simulation-based exercises to enhance SEDM coordination, prepare for emergency response, continue developing regional capabilities and enhance ties to Euro-Atlantic institutions.

Figure 2 illustrates the geographical scale of the SEESIM effort. 


\section{SEESIM 02 Participants}

\section{SEESIM 02 Computer-Assisted Deno \& Exercise}

- Albania

- Bulgaria

- Croatia

- FYR of Macedonia

- Greece (Host Nation)

- Italy (Observer)

- Romania

- SEEBRIG HQ

- Slovenia

- Turkey

- United States (Supporting Nation)

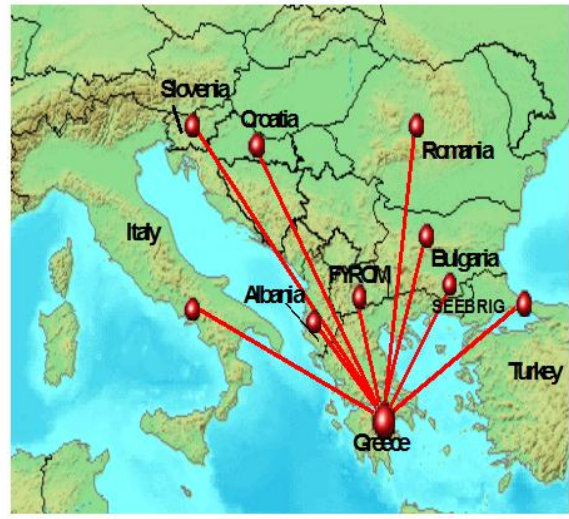

Figure 2: SEESIM 02 Participants.

The scenario developed, and used, for SEESIM 02 was a civil emergency scenario that quickly expanded to involve various agencies in all the participating countries, as illustrated in Figure 3. The close relationship between the concept defined by the NMCC architecture and the actual scenario developed and executed for the SEESIM exercise is evident by comparing these three figures. It is exciting to see the coalescing of these disparate organizations and nations into a single coordinated operation, even if so briefly. A small step toward achieving interoperability may be taking place, thanks to these various players. Another SEESIM exercise is planned for 2004. JTLS will again be used and the main process will be executed in the new Turkish War College M\&S Center in Istanbul, Turkey.

It is important to note that the simulation software, selected to support the SEESIM efforts, is JTLS. The value of using software that is HLA compliant, highly distributable, a NATO and US standard and well documented has not been lost by the participants. Their ability to communicate and work together is further enhanced by the concept of being able to manage the design to accommodate individual $\mathrm{C} 2$ systems over time. The managers of the simulation software are aware of the commercialization of the Run Time Infrastructure (RTI) software and are closely monitoring the various vendors to ensure as much commonality as possible. 


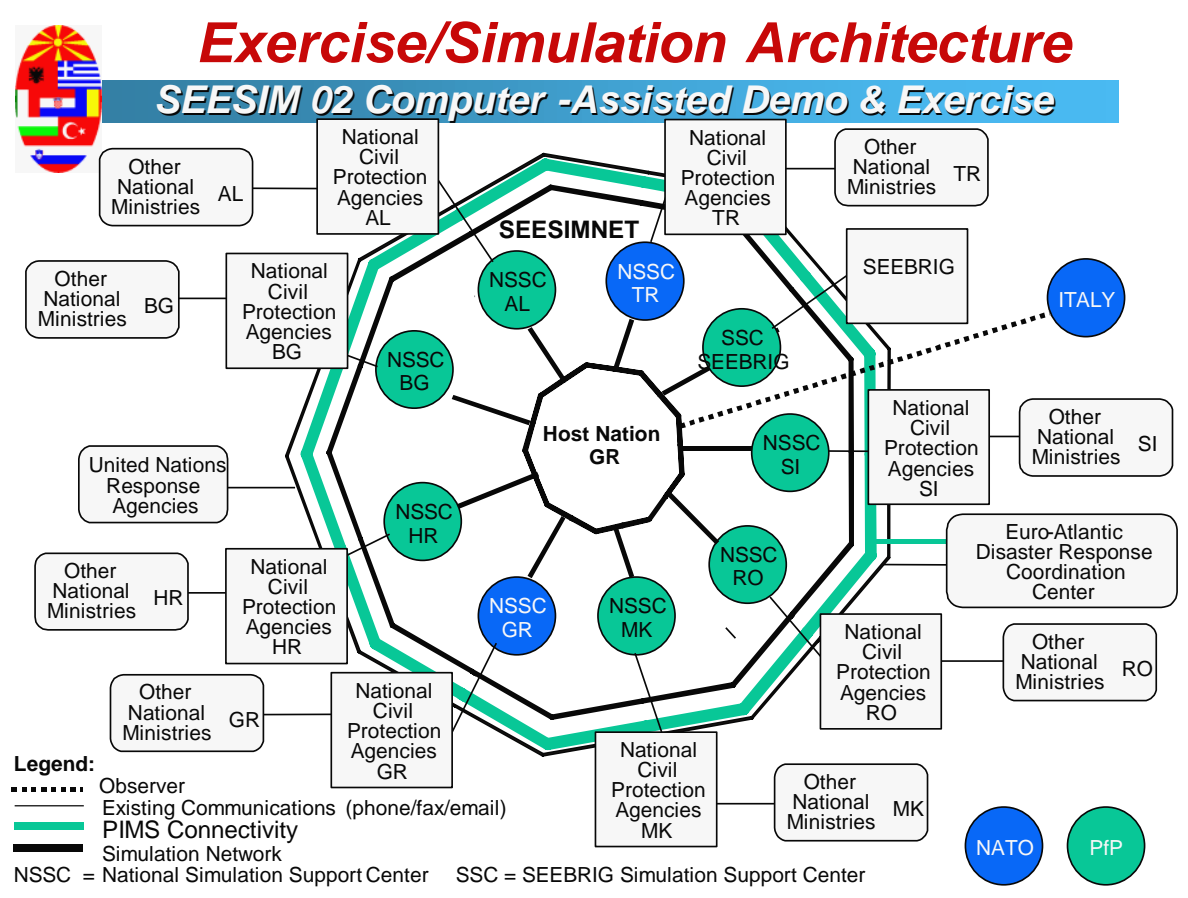

Figure 3: Exercise / Simulation Architecture.

The NATO/NC3A exercise called CANNON CLOUD was held at the US Armed Forces - Europe Warrior Preparation Center, Einsedlerhof, Germany, from 1-15 November. It used a scenario that involved planning and conducting joint operations for a collective defense situation. It was a very large exercise with hundreds of JTLS Work Stations, and illustrated the multi-national capability of this simulation being used in a purely combat support situation for training senior joint, combined and multinational staffs.

The analytical tool used for the STRATOS project is JTLS. This 2-year, $\$ 3,000,000$ USD research effort was in support of the European Cooperation for Long-term In Defence (EUCLID) program. It required a strategic operational simulation to support research goals and JTLS was chosen as their research support tool. The consortium included Italy and Greece and two commercial firms, DATAMAT (lead company, IT) and INTRACOM (GR). The University of Genoa is developing plans to use JTLS in one of their follow-on research efforts in 2003/2004. 


\section{NMCC since 1999}

Once you have secured the area, be sure to tell the enemy

JTLS has continued to mature since 1999. The NMCC program has kept pace with changes in the EU and PfP nations, and with applicable, current technology. It has suffered some delay due to bureaucracy, U.S. policies and changes in management. One crucial ingredient to the NMCC recipe is that they require a solid base of users before establishing their first site. This will change in the near future as more users are identified. The expanded capabilities of a proven theater level simulation system may be the added benefit that the NATO Members, PfP Nations and the Mediterranean Dialogue Countries will view as an added benefit to becoming part of the NMCC program.

\section{Caveat Emptor}

The recent ITEC and I/ITSEC conferences make it dramatically clear that the potential user of simulations must be well versed in the nature of simulations, their proven capabilities, and can match their agencies requirements with the capabilities of the tool. There are numerous vendors, with wonderful displays, that can capture your imagination. In some, perhaps too many, cases "what you see is what you get." The American phrase "look under the hood" is very apropos. Vaporware is another common term. In many cases the vendors have something that is special purpose, but they are advertising it as a general application. This is evident in many publications that are distributed worldwide and that include advertisements and articles praising various simulation techniques and systems that have little, if any validity: Some periodicals such as The National Defense, www.ndia.org, MS\&T, The International Defence Training Journal, www.halldale.com/mst, and I/ITSEC NTSA National Defense, Training and Simulation 2002 - Trends and Technology Review I/ITSEC Exhibits' Guide, include many articles and advertisements that may be misleading. Consider the JSIMS advertising for example.

Some U.S. Service representatives have expressed their concern and dismay on numerous occasions about how the forces have allowed their simulations and training programs to decay. ${ }^{28}$ One representative observed that some high tech gizmos look nice in the laboratory or classroom but that industry and some technologists, i.e. simulation providers, have lost the big picture and the environment in which the tools are to be used.

The Military Operations Research Society (MORS) publishes a monthly newsletter called the Phalanx, which recently included an article co-authored by Dr. P. Allen and Ms. A. Ratzenberger. They were involved in an experiment, called Millennium Challenge 2002 at the Joint Experimentation Directorate of the JFCOM. Dr. Allen 
and Ms. Ratzenberger described situations where they were assured by simulation software developers that their specific application would meet all the specifications defined for their particular part of the experiment. ${ }^{29}$ The result was described in the article, and in part said, "The term 'buyer beware' is as applicable now as it ever was. There are many new models appearing that make many claims about capabilities and what they represent." Users must be astute enough to determine, through any means available, that the tools they intend to use really do meet specifications and are not vaporware. Caveat emptor.

\section{Conclusion}

The need for interoperability continues to be identified as a crucial element in providing more efficient and effective, multi-national and multi-agency operations. The ability to exchange information, coordinate resources, and understanding each participant's capability is paramount to meeting today's challenges on the military and civil battlefields. This paper has attempted to provide examples of the shortcomings. Joint, combined, multinational training is seen as one key to the transformation required to effect interoperability. The newly restructured Atlantic Command is one step of this transformation in the European Theater. The SEESIM demonstration and the CANNON CLOUD exercises are provided as two examples where a simulation engine was used to assist in executing interoperability strategies and tactics. A common architecture, tested and exercised on a regular basis will lead toward interoperability. The simulation engine, used for these and multiple other exercises and analyses annually and which is being upgraded and enhanced continually, is a proven value. It has become a worldwide standard for theater level simulations.

The need for a common simulation-training platform among nations and agencies is essential. There are a large number of platform combinations that may prove effective. A potential architecture to consider, presented herein as an example, is the USAF-ESC NMCC concept combined with the JTLS model. Caveat emptor is recommended throughout system selection to detect the nuances between M\&S and S\&M. A small step toward interoperability. 


\section{Appendix A. The JTLS International User Community}

\section{Current}

The Commonwealth of Australia, Australian Defence Force Warfare Centre

United Arab Eremites M\&S Center, via Coleman Research Corp., Huntsville, Alabama

France: College Interarmees De Defense

Greece: Hellenic National Defense General Staff

Italy: Comando Operativo Interforze (CIMSO), via Marconi, Ltd.

Japan: Japanese Defense Agency, via Mitsubishi Electric Corporation

Republic of Korea: ROK Air University, Taichung, ROK

Thailand: Royal Thai Supreme Command, Joint Staff College

Turkey: TURKISH War Colleges, Istanbul

United Kingdom: Defence Science \& Technology Laboratories

NATO C3 Agency, The Hague, Netherlands

Scheduled for 2003

Taiwan MND

Spain

Malaysia MINDEF

Slovenia

Poland

Oman 


\section{Appendix B. Smoke and Mirrors Defined}

\section{Subject: Smoke and Mirrors, circa late 2002, prior to the U.S. SECDEF announcement that JSIMS funding was to be withdrawn.}

First, I wanted to remind you that I had interacted with JTLS back when I was a RAND employee at the Warrior Preparation Center (1989-1991). You contacted me then regarding how much like my RAND Report on Evolution of Models at the Warrior Preparation Center: Problems and Solutions for Higher-Echelon Exercises, where one of the three primary recommendations was for the WPC to use JTLS for higher-echelon exercises. We discussed the strengths and limitations of various models, and how it was unfortunate that there was a certain amount of prejudice (and not-invented here) syndrome in the field. Later, when I was senior scientist for Cubic Applications Inc. we were trying to get JTLS into NATO/SHAPE exercises and the UK, although both of those immediate opportunities did not pan out. However, over time, you were still able to get JTLS into those exercises, which I believe was a good idea.

When JCM and UCATS were combined in their capabilities to form JCATS, I believe that was a step forward in the level of resolution that could be accomplished across both models. Connecting JTLS to JCATS sounds even more interesting. Now that JTLS is HLA compliant, I do believe the HLA-compliant JTLS-JCATS tool is worth looking into. Other models being examined include the Joint Integrated Contingency Model (JICM), which I helped develop when I was at RAND, but I do believe all viable opportunities should be examined. (I don't think I suffer from the not-invented-here syndrome, and can appreciate other approaches I did not happen to work on!)

Although I have since visited the JEXP to discuss ways to connect Operational Net Assessment tools with IO tools, I am no longer working Joint Experimentation support on a daily basis.

Let me also reply to the issue of legacy versus "new" models. I, for one, do not consider the term "legacy" to be a dirty word (and I hope the article reinforced that viewpoint). As the JWARS developers are finding out the hard way, the legacy algorithms solved a number of problems that they are rediscovering in JWARS and JSIMS, and have yet to be solved in those new models. In my opinion, aggregate model-designers are indeed a rare breed, and the entity-based-everything approach is disastrous for the industry. Entity based applications have their place, as do aggregate models. There is no "one-size fits all" model, in spite of some efforts to make that claim. 
The two models we were referring to in the article were the older LEM-Space model out of USSPACECOM (the first case) and the Entropy-Based Warfare model (the second case). The smoke and mirror aspects were highly prevalent in those two, and it appears to be getting worse. A lot of money was invested in the latter, and it is now being touted as the Holy Grail--and few have noted when the Emperor has no clothes. Do I think JWARS or JSIMS are new or legacy? Since they haven't solved the aggregation problems that we solved many times years ago in the legacy models, then they are new but missing the old boat that got folks across the river before. They did not have experienced modelers helping on the design--moreover, they religiously believed entity-level was the only way to do any analysis, training, or experimentation. The community is suffering immensely under the DARPAsponsored mentality where only entity-level through-the-window simulations mattered--and will continue to suffer for years. A picture may be worth a thousand words, but it can also be the simulation equivalent of an optical illusion. Graphics sells, regardless of what is behind it.

So is JTLS-JCATS legacy? Yes, and no. It has the benefits of being one of the legacy models that solved many of the problems that still plague the JSIMS/JWARS development efforts. Is JTLS-JCATS a new model? In that it talks HLA and runs on Linux, I believe it also has some new elements. So hopefully the JTLS-JCATS combination will get a fair hearing in these upcoming events. I am sorry that so much money was wasted on the JSIMS and JWARS efforts, when a small team of experienced modelers could have accomplished so much more with even a fraction of those funds. But that's politics. The voices in the wilderness warned of the coming train wreck, but the money-providers were enamored with the smoke and mirrors. That is one reason I am no longer in that field--good money continues to flow after badly expended money, and there seems to be a belief that unless all funds fill the one basket, the one basket will never succeed. (That's partly true, for if all the funds go to one basket, there are no alternatives left to compete for the future of modeling and simulation--but the win is by default and not based on success.) Due to my new field, I will not likely be at I/ITSEC this year.

Any way, I believe I have said my piece and "set the world to rights"--if only it were that easy! Good luck and best wishes on getting JTLS-JCATS marketed and used. As I mentioned in my previous e-mail, it is good to see that both you and JTLS are still alive and kicking. My contact information is below.

Author to remain anonymous. 


\section{Notes:}

Unknown scholar.

Appendix B. Smoke and mirrors defined.

Patrick D. Allen and Annette C. Ratzenberger, "Outputs Should Not Equal Inputs," Phalanx 35, 3 (September 2002): 9.

Mr. Brian Gregg, JTLS PM, JW1910, Joint Warfighting Center, U.S. Joint Forces Command, Suffolk, VA, greggb@jwfc.jfcom.mil.

See Enterprise Team, <www.msiac.dmso.mil/enterprise/default.asp> (3 October 2003) or email the webmaster at webmaster@msiac.dmso.mil.

The list of International JTLS Users is included in Appendix A.

The database values managed the simulation process.

"Advance Planning Briefing to Industry," MS\&T Magazine, Issue 6 (2002): 47.

Robertson, The Right honorable George Islay MacNeill, Lord of Port Allen, "The Transatlantic Security Agenda," Joint Force Quarterly, (Washington, D.C.: Institute for National Strategic Studies, U.S. National Defense University, Autumn/Winter 2001): 3439.

Thomas-Durell Young, "NATO Command and Control for the $21^{\text {st }}$ Century," Joint Force Quarterly, (Washington, D.C.: Institute for National Strategic Studies, U.S. National Defense University, Autumn/Winter 2001): 40-45; European Program Manager for the Civil-Military Relations, U.S. Naval Postgraduate School, Monterey, CA.

1 John Gordon IV, Bruce Nardulli, and Walter L. Perry, "The Operational Challenges of Task Force Hawk," Joint Force Quarterly, (Washington, D.C.: Institute for National Strategic Studies, U.S. National Defense University, Autumn/Winter 2001): 52-57.

K. Dehaies, Defense News, 26 November 2001.

National Military Command Center, Concept of Operations (Hanscom AFB, MA: USAF Electronic Systems Center, 18 August 2001), Esc.fa.cmb@hanscom.af.mil. POC Major S. Lausman, scott.lausman@hanscom.af.mil.

W. H. Switzer PhD, Distributed Training and Distributed Simulations: Imperatives for Success in Military Operations Other than War (Washington, D.C.: AB Technologies, Inc.), undated.wswitzer@msosa.dmso.mil.

National Military Command Center Concept of Operations, Draft (22 November 1999).

Gordon Adams, "Inside View - Aftermath of Prague. New Strategy Hinges on U.S. Trade Reform," Defense News, 16 December 2002, 17.

National Military Command Center Technical Architecture Description, (Hanscom AFB, MA: USAF Electronic Systems Center, 21 August 2000).

8 The Joint Theater Level Simulation, presented by Dr. R. J. Roland and demonstrated by Mr. R. Kalinyak, R\&A Systems Engineer.

See http://www.rolands.com/jtls.html.

See http://www.jfcom.mil.

See Appendix A for a list of International JTLS Users.

Appendix A is the list of International JTLS Users.

http://www.pacom.mil.

http://www.nato.int. 
http://www.centcom.mil.

Mr. Brian Gregg, JTLS PM.

David F. Taylor, et al, NC3A Support for Theatre Missile Defence Operations in NATO Exercise CANNON CLOUD 2002 (CCO2), (The Hague, Netherlands: NATO Consultation, Command and Control Agency), David.Taylor@nc3a.nato.int. 9 December 2001.

Allen and Ratzenberger, "Outputs Should Not Equal Inputs."

RONALD J. ROLAND, Ph.D., Information Systems Management, University of Nebraska, Lincoln, NE, 1980 (dissertation on Using Artificial Intelligence Techniques to Design and Evaluate Decision Support Systems); M.S., Computer Science, University of Hawaii, Honolulu, HI, 1971; B.S., Mathematics, Colorado State University, Fort Collins, CO, 1969. Dr. Roland is the co-founder and President of ROLANDS \& ASSOCIATES corporation (R\&A). He has managed the development of several computer simulations including the Joint Theater Level Simulation (JTLS), a real-time, interactive wargaming system originally sponsored by JCS/J-8 for contingency plan analysis, Planning Alternatives for Interdicting National Terrorism (PAINT), a one sided, real time, resource allocation, combat model, and the Advanced Land Air Research Model (ALARM), a systematic research model that was developed to evaluate future planning cycles for mobile ICBMs using Bayesian Statistics. JTLS is distributed and supported on a worldwide basis by R\&A through a Cooperative Research And Development Agreement (CRADA). It is used for command post exercise support, analyses of contingency and operational plans, and examination of potential conflict situations. PAINT was used to develop counter terrorism plans, and ALARM was a research project designed to investigate organization structures, communications flows and movement of combat forces. Dr. Roland was a Professor in the Computer Science Department of the Naval Postgraduate School, Monterey, California. He designed and presented courses in computer science, command control, and information systems. His research area was artificial intelligence and advanced technology for management decision support systems. Dr. Roland was the project manager and director for acquisition, installation, and implementation of the School's first modeling, simulation and war-gaming laboratory. Dr. Roland's career in the U.S. Air Force included nuclear exchange simulations, management of a real time, computer enhanced, C2. Additional information is available at www.rolands.com.

E-mail:President@rolands.com. 